\title{
Chronique bibliographique
}

Les publications récentes (2006-2008) sur la préhistoire et l'archéologie historique de la Basse-Normandie

\section{Anne Ropars}

\section{(2) OpenEdition}

1 Journals

Édition électronique

URL : http://journals.openedition.org/rao/739

DOI : $10.4000 /$ rao.739

ISBN : 978-2-7535-1608-3

ISSN : $1775-3732$

Éditeur

Presses universitaires de Rennes

Édition imprimée

Date de publication : 20 décembre 2008

Pagination : $345-357$

ISBN : 978-2-7535-0789-0

ISSN : 0767-709X

\section{Référence électronique}

Anne Ropars, «Chronique bibliographique », Revue archéologique de l'Ouest [En ligne], 25 | 2008, mis en ligne le 20 décembre 2008, consulté le 03 décembre 2020. URL : http://journals.openedition.org/rao/ 739 ; DOl : https://doi.org/10.4000/rao.739 


\title{
Chronique bibliographique
}

\section{Les publications récentes (2006-2008) sur la prébistoire et l'archéologie historique de la Basse-Normandie}

\author{
Anne Ropars*
}

\section{Généraltés}

\section{ET PUBLICATIONS DIACHRONIQUES}

ALLART, E, 2006. - Prospection et parcellaire : hypothèses et limites d'interprétation sur le futur tracé autoroutier Falaise - Sées. Archéologie et prospection en Basse-Normandie. Caen, Société des Antiquaires de Normandie (Mémoire XXXVIII), p. 35-49.

(anonyme), 2008 - Bilans et préconisations : étude de l'état de conservation matériel des biens culturels mobiliers du patrimoine public de Basse-Normandie. Caen, Centre régional de conservation-restauration des biens culturels de Basse-Normandie, $54 \mathrm{p}$.

BLONDAUX, J., ALDUC-LE BAGOUSSE, A., DEMONDION, X., DELAHAYE, F. et NIEL, C., 2007 - Maladie hyperostotique et maladie goutteuse, une diathèse familiale en Normandie: Thaon, Calvados. Bulletins et Mémoires de la Société d'Anthropologie de Paris, 19 (fasc. 1-2) [en ligne].

CARPENTIER, V., GHESQUIÈRE, E. et MARCIGNY, C., 2007 - Archéologie en Normandie. Rennes, éditions OuestFrance/INRAP, (collection Histoire), 127 p.

CANU, B., 2006 - Les moulins du Clos du Cotentin : contribution à l'étude d'un facteur indicateur de l'évolution du territoire et de ses contingences naturelles et anthropiques. In situ. Le patrimoine rural ( $2^{e}$ partie) [revue de l'inventaire en ligne], $\mathrm{n}^{\circ} 6$.

CHANCEREL, A., MARCIGNY, C. et GHESQUIÈRE, E. (dir.), 2006 - Le plateau de Mondeville (Calvados) du Néolithique à l'âge du Bronze. Paris, Maison des Sciences de l'Homme (Documents d'Archéologie française; 99), 208 p.

(collectif), 2006 - Bilan scientifique régional 2005. DRAC de Basse-Normandie. Caen, Ministère de la Culture et de la Communication, $158 \mathrm{p}$.
JUHEL, V. (dir.), 2006 - Archéologie et prospection en BasseNormandie. Caen, Société des Antiquaires de Normandie (Mémoire XXXVIII), 255 p.

DELRIEU, F. et DESLOGES, J. (dir.), 2007 (avec la coll. de QUÉVILLON, S.) - ArchéOrne, 250 ans d'archéologie dans l'Orne (catalogue d'exposition). Cabourg, éditions Cahiers du Temps, $143 \mathrm{p}$.

DESHAYES, J., 2006 - Identification des matériaux et étude du bâti : l'exemple du Clos du Cotentin. In situ, Le patrimoine rural ( $2^{e}$ partie) [revue de l'inventaire en ligne], 6.

FOURNIER, D., 2006 - Toponymie et archéologie. Archéologie et prospection en Basse-Normandie. Caen, Société des Antiquaires de Normandie (Mémoire XXXVIII), p. 1-11.

DUJARDIN, L., 2006 - L'utilisation de la pierre dans la construction rurale en Normandie aux époques médiévales et modernes. In situ, Le patrimoine rural ( $2^{e}$ partie) [revue de l'Inventaire en ligne], $\mathrm{n}^{\circ} 6$.

FOSSE, G., 2008 - Un endroit quelconque du littoral de la pointe de la Hague : Le Hâvre de Bombec à Saint-Germain-des-Vaux, étude historique, ethnographique et archéologique. In, MARCIGNY, C. (dir.), Archéologie, Histoire et Anthropologie de la presqu'île de la Hague (Manche) : analyse sur la longue durée d'un espace naturel et social cohérent. Troisième année de recherche, 2007 (rapport de PCR). Beaumont-Hague, Le Tourp, p. 79-84.

GHESQUIÈRE, E., 2007 - Le diagnostic archéologique sur l'autoroute A 88, section Falaise - Argentan. Bulletin de la Société historique et archéologique de l'Orne, 126 ( ${ }^{\circ}$ 3-4), p. 8-28.

GRALL, J., 2006 - Inventaire des archives de la Société des Antiquaires de Normandie (an IX-1966): Fonds déposé aux Archives départementales du Calvados, répertoire numérique détaillé de la sous-série 83 F. Caen, Société des Antiquaires de Normandie (Mémoire XXXIX), 150 p.

* Service régional de l'Archéologie de Basse-Normandie, Caen. 
JARRY, T, 2006 - Evaluer, inventorier, exploiter : le Rotulus de denariis de l'abbaye Saint-Etienne de Caen (XIII ${ }^{\mathrm{e}}$ siècle). Tabularia. Sources écrites de la Normandie médiévale. Etudes [publication en ligne du CRAHM], 6, p. 1-23.

JEANNE, L., DUCLOS, C. et LE GAILLARD, L., 2007 - Prospections diachroniques, Nord-Cotentin. Bulletin du Groupe de Recherches archéologiques du Cotentin, 12, 2007. p. 41-42.

LEBAS, P., PONTVIANNE, C. et SAVARY, X., 2006 - Le silex en Basse-Normandie : de la matière à la manière de bâtir. Caen, éditions CRéCET, 48 p.

LEPRÉVOST, T., 2006 - Caen, un musée pour la Normandie. Patrimoine normand, 58, p. 27-33.

LEROUVILLOIS, R., 2006 - Historique sommaire des recherches anciennes. Seconde partie : de la fin du XIX ${ }^{\mathrm{e}}$ siècle à l'époque actuelle. In, MARCIGNY, C. (dir.), Archéologie, Histoire et Anthropologie de la presqu'ïle de la Hague (Manche) : analyse sur la longue durée d'un espace naturel et social cohérent (deuxième année de recherche, rapport de PCR). Beaumont-Hague, Le Tourp, p. 41-50.

LESPEZ, L., CADOR, J.-M. et GERMAINE, M.-A., 2006 Gestion de l'eau et trajectoire des petites vallées, exemples normands. Interactions nature-société : analyses et modèles : Colloque international, la Baule, 3-6 mai 2006. Nantes, LETG, 2006. $6 \mathrm{p}$.

LESPEZ, L., CARPENTIER, V., GARNIER, E., MARCIGNY, C., COSTA, S. et AGASSE, E., 2006 - Gestion de l'eau et dynamique des paysages du Néolithique à nos jours. Etude des basses vallées côtières dans le nord-ouest de la France. (Rapport scientifique et financier au Ministère de la Recherche). Caen, GEOPHEN/UMR 6554 du CNRS, 145 p.

LESPEZ, L., CLET-PELLERIN, M., DAVIDSON, R., DÉMAREST, T., MENESSON, B. et DAMOURETTE, C., 2006 - L'environnement de la Mare de Vauville, de l'étude de la longue durée au développement durable : premiers résultats. In, MARCIGNY, C. (dir.), Archéologie, Histoire et Anthropologie de la presqu'ile de la Hague (Manche) : analyse sur la longue durée d'un espace naturel et social cohérent. (deuxième année de recherche, rapport de PCR). Beaumont-Hague, Le Tourp, p. 7-14.

MADELINE, P., 2006 - Effets paysagers des transformations agricoles et rurales dans le sud du Pays d'Auge. In Situ, Le patrimoine rural ( $2^{e}$ partie) [revue de l'Inventaire en ligne], 6.

MARCIGNY, C., FLOTTÉ, D., DESLOGES, J. et RENAULT, V., 2006 - «Les petits ruisseaux font les grandes rivières " : l'exemple de la périphérie sud de Caen (Calvados). Les Nouvelles de l'Archéologie, 104-105, p. 61-63.

MARCIGNY, C. (dir.), GHESQUIÈRE, E. et JUHEL, L., 2006 - Les collections préhistoriques et gallo-romaines du Muséum Emmanuel Liais. Éditions de la Ville de Cherbourg (collection Unica), 75 p.
MARCIGNY, C., GHESQUIÈRE, E., FLOTTÉ, D. et RENAULT, V., 2006 - Prospection mécanique et archéologie préventive en milieu rural : un exemple dans le département de la Manche (la déviation de Saint-Lô). Archéologie et prospection en Basse-Normandie. Caen, Société des Antiquaires de Normandie (Mémoire XXXVIII), p. 31-34.

MARCIGNY, C. et BOSTYN, F., 2007 - La fin du $x^{e}$ siècle : naissance de l'archéologie préventive. In, MARCIGNY, C., GHESQUIÈRE, E. et DESLOGES, J. (dir.), La hache et la meule : les premiers paysans du Néolithique en Normandie (catalogue d'exposition). Le Hâvre, éditions du Muséum d'Histoire naturelle, p. 32-33.

MARCIGNY, C., CARPENTIER, V. et GHESQUIÈRE, E., 2007 - La première année de recherche (2005) du projet collectif de recherche "Archéologie, Histoire et Anthropologie de la presqu'île de la Hague (Manche) ». Bulletin du Groupe de Recherches archéologiques du Cotentin, 12, p. 44-47.

MARCIGNY, C., GHESQUIÈRE, E., GALLOUIN, E. et VIPARD, L., 2007 - Archéologie d'un site de hauteur de l'Orne, l'éperon d'Exmes. Bulletin de la Société historique et archéologique de l'Orne, 126 (n³-4), p. 65-78.

MARCIGNY, C., GHESQUIÈRE, E. et JUHEL, L., 2007 - L'abri sous roche de "La Jupinerie " à Omonville-la-Petite. Bulletin du Groupe de Recherches archéologiques du Cotentin, 12, p. 14-21.

MORAND, F., 2007 (avec la coll. de DELRIEU, F. et ZAOUR, N.) Prospection archéologique en forêt de Bellême. Bulletin de la Société historique et archéologique de l'Orne, 126 (n 3-4), p. 29-47.

RIDEL, E., 2008 - La Hague, une terre Viking? Du mythe à la réalité. In, MARCIGNY, C. (dir.), Archéologie, Histoire et Anthropologie de la presquïle de la Hague (Manche) : analyse sur la longue durée d'un espace naturel et social cohérent. Troisième année de recherche, 2007 (rapport de PCR). Beaumont-Hague, Le Tourp, p. 63-71.

SAN JUAN, G. et WATTÉ, J.-P., 2007 - Le Muséum du Havre et la Société géologique de Normandie témoins privilégiés de la recherche préhistorique en Normandie. In, MARCIGNY, C., GHESQUIÈRE, E. et DESLOGES, J. (dir.), La hache et la meule : les premiers paysans du Néolithique en Normandie (catalogie d'exposition). Le Havre, éditions du Muséum d'Histoire naturelle, p. 25-30.

VILGRAIN-BAZIN, G., 2007 - Les occupations littorales du Nord-Cotentin : prospections diachroniques. Bulletin $d u$ Groupe de Recherches archéologiques du Cotentin, 12, p. 4243.

VILGRAIN-BAZIN, G. 2008 - Hâvre de Bombec, St-Germaindes-Vaux. In, MARCIGNY, C. (dir.), Archéologie, Histoire et Anthropologie de la presqülle de la Hague (Manche) : analyse sur la longue durée d'un espace naturel et social cohérent. Troisième année de recherche, 2007 (rapport de PCR). Beaumont-Hague, Le Tourp, p. 85-92. 
SERVICE DEPARTEMENTAL D'ARCHEOLOGIE DU CALVADOS, 2006 - Vieux-la-Romaine. Musée et sites archéologiques. Rennes, éditions Ouest-France (coll. Monographies Patrimoine), $32 \mathrm{p}$.

HINCKER, V. et DRON, J.-L., 2006 - 7000 ans d'histoire. Gestes funéraires de la Préhistoire à nos jours en Basse-Normandie. Condé-sur-Noireau, Editions NEA, 160 p.

\section{Paléolithique - Mésolithique}

CHARRAUD, F., 2008 - Auderville (Manche) « Le Sémaphore », fouille d'un amas de débitage attribué au Mésolithique final. In, MARCIGNY, C. (dir.), Archéologie, Histoire et Anthropologie de la presquïle de la Hague (Manche) : analyse sur la longue durée d'un espace naturel et social cohérent. Troisième année de recherche, 2007 (rapport de PCR). Beaumont-Hague, Le Tourp, p. 28-39.

CLIQUET, D., 2006 - Apport des prospections à la connaissance des premiers peuplements de la Basse-Normandie. Archéologie et prospection en Basse-Normandie. Caen, Société des Antiquaires de Normandie (Mémoire XXXVIII), p. 83-92.

CLIQUET, D., 2007 - Approvisionnement en matières premières lithiques et végétales, et en ressources alimentaires en Normandie (France) entre le stade 7 et le stade 3. In, MONCEL, M.-H., MOIGNE, A.-M., ARZARELLO, M. et PERETTO, C., Aires d'approvisionnement en matières premières et aires d'approvisionnement en ressources alimentaires: approche intégrée des comportements (Actes $\mathrm{du} X \mathrm{XV}^{\mathrm{e}}$ congrès mondial de l'UISPP, Lisbonne, 2006). Oxford, Archaeopress (BAR International Series; 1725), p. 93-102.

CLIQUET, D., 2007 - Préhistoire ancienne : les chasseurscueilleurs, du Paléolithique au Mésolithique. In, DELRIEU, F. et DESLOGES, J. (dir.), avec la coll. De QUÉVILLON, S., ArchéOrne : 250 ans d'archéologie dans l'Orne (catalogue d'exposition). Cabourg, éditions Cahiers du temps, p. 13-35.

CLIQUET, D., LAUTRIDOU, J.-P., CASPAR, J.-P., LASSEUR, E., LORREN, P., MERCIER, N. et RIVARD, J.-J., 2007

- Et si ce n'était pas Néandertal? Les ateliers bifaciaux de «l'Espace d'Écouché » (Orne, France), il y a environ 40600 ans. Bulletin de la Société historique et archéologique de l'Orne, 126 (no 3-4), p. 49-63.

CLIQUET, D., LAUTRIDOU, J.-P., MERCIER, N., RIVARD J.-J. et LORREN, P., 2007 - Les derniers Néandertaliens de la région de Rânes. In, DELRIEU, F. et DESLOGES, J. (dir.), avec la coll. De QUÉVILLON, S., ArchéOrne : 250 ans d'archéologie dans l'Orne (catalogue d'exposition). Cabourg, éditions Cahiers du temps, p. 27.

CLIQUET, D. ET LEPORTIER, J., 2007 - Le biface traingulaire de Montgaroult. In, DELRIEU, F. et DESLOGES, J. (dir.), avec la coll. de QUÉVILLON, S., ArchéOrne : 250 ans d'archéologie dans l'Orne (catalogue d'exposition). Cabourg, éditions Cahiers du temps, p. 26.

CLIQUET, D. et LORREN, P., 2007 - Industrie acheuléenne, Commeaux, Argentan. In, DELRIEU (F.), DESLOGES (J.) (dir.), avec la coll. de QUÉVILLON (S.), ArchéOrne : 250 ans d'archéologie dans l'Orne (catalogue d'exposition). Cabourg, éditions Cahiers du temps, p. 20-21.

CLIQUET, D. et PAPILLON, J., 2007 - Le Mésolithique final du canton de Carrouges. In, DELRIEU, F. et DESLOGES, J. (dir.), avec la coll. de QUÉVILLON, S., ArchéOrne : 250 ans d'archéologie dans l'Orne (catalogue d'exposition). Cabourg, éditions Cahiers du temps, p. 34-35.

CLIQUET, D., PRUVOST, P. et PAPILLON, J., 2007 - Le Paléolithique supérieur final de la vallée de l'Avre. In, DELRIEU, F. et DESLOGES, J. (dir.), avec la coll. de QUÉVILLON, S., ArchéOrne: 250 ans d'archéologie dans l'Orne (catalogue d'exposition). Cabourg, éditions Cahiers du temps, p. 30-31.

CLIQUET, D. et RIVARD, J.-J., 2007 - Le Paléolithique moyen de l'espace Rânes-Écouché. In, DELRIEU, F. et DESLOGES, J. (dir.), avec la coll. de QUÉVILLON, S., ArchéOrne : 250 ans d'archéologie dans l'Orne (catalogue d'exposition). Cabourg, éditions Cahiers du temps, p. 22-23.

GHESQUIÈRE, E. et DÉDOUIT, J.-J., 2006 - Mise en évidence de deux ensembles tardiglaciaires à Curcy-sur-Orne. Archéologie et prospection en Basse-Normandie. Caen, Société des Antiquaires de Normandie (Mémoire XXXVIII), p. 93100.

GHESQUIÈRE, E., DÉDOUIT, J.-J. et THOMAS, Y., 2006 - Le Mésolithique ancien dans le Calvados. Archéologie et prospection en Basse-Normandie. Caen, Société des Antiquaires de Normandie (Mémoire XXXVIII), p. 101-111.

GHESQUIÈRE, E., 2006 - L’occupation mésolithique de Perréval à Jobourg (Manche). In, MARCIGNY, C. (dir.), Archéologie, Histoire et Anthropologie de la presquïle de la Hague (Manche) : analyse sur la longue durée d'un espace naturel et social cohérent. (Deuxième année de recherche, rapport de PCR), BeaumontHague, Le Tourp, p. 17-33.

MAÎTRE, J., 2008 - Approche microtopographique appliquée aux armatures mésolithiques de Perréval 2 à Jobourg (Cotentin). In, MARCIGNY, C. (dir.), Archéologie, Histoire et Anthropologie de la presquïle de la Hague (Manche) : analyse sur la longue durée d'un espace naturel et social cohérent. Troisième année de recherche, 2007 (rapport de PCR). Beaumont-Hague, Le Tourp, p. 9-27.

PIEL-DESRUISSEAUX, J.-L., 2007 - Les éclats de Néanderthal. Chez les artisans de la préhistoire. Paris, éditions Dunod (coll. Quai des Sciences), $200 \mathrm{p}$. 


\section{NÉOLITHIQUe}

LEPREVOST, T. , 2006 - Colombiers-sur-Seulles : le plus vieux monument de Normandie. Patrimoine normand, 59, p. 1618.

SERVICE DEPARTEMENTAL D'ARCHEOLOGIE DU CALVADOS, 2006 - Tumulus de Colombiers-sur-Seulles : quand un monument préhistorique favorise le retour de l'emploi. Journal du Calvados, 83, p. 32-33.

BEDAULT, L. et HACHEM, L., 2007 - L'élevage et la chasse dans la société néolithique. In, MARCIGNY, C., GHESQUIÈRE, E. et DESLOGES, J. (dir.), La hache et la meule: les premiers paysans du Néolithique en Normandie (catalogue d'exposition). Le Havre, éditions du Muséum d'Histoire naturelle du Havre, p. 61.

BESNARD-VAUTERIN, C.-C., ARBOGAST R.-M. et CHANCEREL, A., 2006 - Une fosse du Néolithique récent à dépôts d'animaux à l'Etoile (Mondeville). In, CHANCEREL, A., MARCIGNY, C. et GHESQUIÈRE, E. (dir.), Le plateau de Mondeville (Calvados) du Néolithique à l'àge du Bronze. Paris, Maison des Sciences de l'Homme (Documents d'Archéologie française, 99), p. 93-97.

BILLARD, C., 2007 - L'habitat néolithique de Colombelles « Le Lazzaro "(Calvados). In, MARCIGNY, C., GHESQUIÈRE, E. et DESLOGES, J. (dir.), La hache et la meule : les premiers paysans du Néolithique en Normandie (catalogue d'exposition). Le Havre, éditions du Muséum d'Histoire naturelle du Havre, p. 55.

BILLARD, C., 2007 - Les pratiques funéraires au Néolithique ancien. In, MARCIGNY, C., GHESQUIÈRE, E. et DESLOGES, J. (dir.), La hache et la meule : les premiers paysans du Néolithique en Normandie (catalogue d'exposition). Le Havre, éditions du Muséum d'Histoire naturelle du Havre, p. 72-77.

CHANCEREL, A., 2007 - La sépulture à entrée latérale de la Table-au-Diable à Passais-la-Conception. In, MARCIGNY, C., GHESQUIÈRE, E. et DESLOGES, J. (dir.), La hache et la meule : les premiers paysans du Néolithique en Normandie (catalogue d'exposition). Le Havre, éditions du Muséum d'Histoire naturelle du Havre, p. 146.

CHANCEREL, A., 2007 - Le mégalithisme des Iles Chausey. In, MARCIGNY, C., GHESQUIÈRE, E. et DESLOGES, J. (dir.), La hache et la meule : les premiers paysans du Néolithique en Normandie (catalogue d'exposition). Le Havre, éditions du Muséum d'Histoire naturelle du Havre, p. 148.

CHANCEREL, A., GHESQUIÈRE, E. et MARCIGNY, C., 2006 - L'enclos du Néolithique récent/Bronze ancien du MIR (Mondeville). In, CHANCEREL, A., MARCIGNY, C. et GHESQUIÈRE, E. (dir.), Le plateau de Mondeville (Calvados) du Néolithique à l'âge du Bronze. Paris, Maison des Sciences de l'Homme (Documents d'Archéologie française, 99), p. 99-110.
CHANCEREL, A., MARCIGNY, C. et GHESQUIÈRE, E., 2006 - L'occupation du Néolithique moyen II de la ZI Sud (Mondeville, Grentheville). In, CHANCEREL, A., MARCIGNY, C. et GHESQUIÈRE, E. (dir.), Le plateau de Mondeville (Calvados) du Néolithique à l'âge du Bronze. Paris, Maison des Sciences de l'Homme (Documents d'Archéologie française, 99), p. 55-92.

CHANCEREL, A. et GHESQUIÈRE, E., 2006 - La maison danubienne du Haut Saint-Martin. In, CHANCEREL, A., MARCIGNY, C. et GHESQUIÈRE, E. (dir.), Le plateau de Mondeville (Calvados) du Néolithique à l'âge du Bronze. Paris, Maison des Sciences de l'Homme (Documents d'Archéologie française, 99), p. 25-53.

CLÉMENT-SAULEAU, S. et RAVON, E., 2007.- La céramique du Néolithique ancien. In, MARCIGNY, C., GHESQUIÈRE, E. et DESLOGES, J. (dir.), La hache et la meule : les premiers paysans du Néolithique en Normandie (catalogue d'exposition). Le Havre, éditions du Muséum d'Histoire naturelle du Havre, p. 62-63.

DESLOGES, J., 2007 - De la mine à la hache. In, MARCIGNY, C., GHESQUIÈRE, E. et DESLOGES, J. (dir.), La hache et la meule : les premiers paysans du Néolithique en Normandie (catalogue d'exposition). Le Havre, éditions du Muséum d'Histoire naturelle du Havre, p. 117-123.

DESLOGES, J., 2007 - L'homme et le milieu : les comportements face aux matières premières lithiques. In, MARCIGNY, C., GHESQUIÈRE, E. et DESLOGES, J. (dir.), La hache et la meule : les premiers paysans du Néolithique en Normandie (catalogue d'exposition). Le Havre, éditions du Muséum d'Histoire naturelle du Havre, p. 64-71.

DESLOGES, J., 2007 - Les longues sépultures à l'origine des tombes monumentales. In, MARCIGNY, C., GHESQUIÈRE, E. et DESLOGES, J. (dir.), La hache et la meule : les premiers paysans du Néolithique en Normandie (catalogue d'exposition). Le Havre, éditions du Muséum d'Histoire naturelle du Havre, p. $130-131$.

DESLOGES, J., 2007 - Néolithique : les premiers agriculteurs. In, DELRIEU, F. et DESLOGES, J. (dir.), avec la coll. de QUÉVILLON, S., ArchéOrne: 250 ans d'archéologie dans l'Orne (catalogue d'exposition). Cabourg, éditions Cahiers du temps, p. 37-63.

DIETSCH-SELLAMI, M.-F., 2007 - Les plantes cultivées du début du Néolithique en Normandie. In, MARCIGNY, C., GHESQUIÈRE, E. et DESLOGES, J. (dir.), La hache et la meule : les premiers paysans du Néolithique en Normandie (catalogue d'exposition). Le Havre, éditions du Muséum d'Histoire naturelle du Havre, p. 59.

DIETSCH-SELLAMI, M.-F., 2007 - L'utilisation des plantes sauvages au Néolithique dans le nord-ouest de la France : témoignages carpologiques. In, BESSE, M. (dir.), Sociétés néolithiques : des faits archéologiques aux fonctionnements socio-écono- 
miques (Actes du $27^{\mathrm{e}}$ colloque interrégional sur le Néolithique, Neuchâtel 2005). Lausanne, Cahiers d'Archéologie romande, 108, p. 127-136.

DRON, J.-L. et LE GOFF, I., 2007 - Des architectures monumentales pour les morts : mémoire et pouvoir. In, MARCIGNY, C., GHESQUIÈRE, E. et DESLOGES, J. (dir.), La hache et la meule : les premiers paysans du Néolithique en Normandie (catalogue d'exposition). Le Havre, éditions du Muséum d'Histoire naturelle du Havre, p. 128-147.

FROMONT, N., MAINGAUD, A., COUTARD, S., LECLERC, G., BOHARD, B., THOMAS, Y. et CHARRAUD, F., 2006 - Un site d'acquisition du schiste pour la fabrication d'anneaux au Néolithique ancien à Saint-Germain-du-Corbéis, "L'Ermitage ". Bulletin de la Société préhistorique française, $103\left(\mathbf{n}^{\circ} \mathbf{1}\right)$, p. 49-70.

FROMONT, N., 2007 - L'artisanat des anneaux en schiste à la fin du Néolithique ancien. In, MARCIGNY, C., GHESQUIÈRE, E. et DESLOGES, J. (dir.), La hache et la meule : les premiers paysans du Néolithique en Normandie (catalogue d'exposition). Le Havre, éditions du Muséum d'Histoire naturelle du Havre, p. 70-71.

FROMONT, N., 2007 - Les parures en schiste : premier artisanat de l'Orne. In, DELRIEU, F. et DESLOGES, J. (dir.), avec la coll. de QUÉVILLON, S., ArchéOrne : 250 ans d'archéologie dans l'Orne (catalogue d'exposition). Cabourg, éditions Cahiers du temps, p. 41.

FROMONT, N., 2008 - Les anneaux du Néolithique bas-normand et du nord-Sarthe : production, circulation et territoires. Bulletin de la Société préhistorique française, 105 ( $\left.{ }^{\circ} \mathbf{1}\right)$, p. 55-86.

GHESQUIÈRE, E., 2007 - Un site du Néolithique moyen à Argentan : le Grand Beaulieu. In, DELRIEU, F. et DESLOGES, J. (dir.), avec la coll. De QUÉVILLON, S., ArchéOrne : 250 ans d'archéologie dans l'Orne (catalogue d'exposition). Cabourg, éditions Cahiers du temps, p. 56-57.

GHESQUIÈRE, E., JUHEL, L. ET MARCIGNY C., 2006

- L'abri de "la Jupinerie " à Omonville-la-Petite : l'occupation du Néolithique moyen I (Hague, Manche), Journée "Civilisations atlantiques et Archéosciences", Rennes 8 avril 2006 (résumés des communications). Rennes, UMR 6566, p. 21-23.

GHESQUIÈRE, E. et MARCIGNY, C., 2007 - «Les derniers hommes libres " : la question de la colonisation danubienne et du devenir des derniers chasseurs-cueilleurs. In, MARCIGNY, C., GHESQUIÈRE, E. et DESLOGES, J. (dir.), La hache et la meule : les premiers paysans du Néolithique en Normandie (catalogue d'exposition). Le Havre, éditions du Muséum d'Histoire naturelle du Havre, p. 44-49.

GHESQUIÈRE, E. et MARCIGNY, C., 2007 - La ruée vers l'Ouest: la maison, le village et la vie quotidienne. In, MARCIGNY, C., GHESQUIÈRE, E. et DESLOGES, J. (dir.), La hache et la meule : les premiers paysans du Néolithique en Normandie (catalogue d'exposition). Le Havre, éditions du Muséum d'Histoire naturelle du Havre, p. 50-63.

GHESQUIÈRE, E. et MARCIGNY, C., 2007 - Les nouvelles formes de l'habitat et l'ouverture du territoire. In, MARCIGNY, C., GHESQUIÈRE, E. et DESLOGES, J. (dir.), La hache et la meule : les premiers paysans du Néolithique en Normandie (catalogue d'exposition). Le Havre, éditions du Muséum d'Histoire naturelle du Havre, p. 93-111.

JUHEL, L., GHESQUIÈRE, E. et MARCIGNY, C., 2006 - L'abri sous roche Néolithique moyen de la Jupinerie (Omonville-la-Petite, Manche). Internéo, 6, p. 55-66.

JUHEL, L., GHESQUIÈRE, E. et MARCIGNY, C., 2007 avec la coll. de CASPAR, J.-P., CLÉMENT-SAULEAU, $S$. et LESPEZ, L., L'abri sous roche Néolithique moyen de la Jupinerie (Omonville-la-Petite, Manche). Internéo, 6, p. 5566.

JUHEL, L. et MARCIGNY, C., 2007 - les occupations de l'abrisous-roche de la Jupinerie à Omonville-la-Petite (50). Le Viquet, 157, p. 25-26.

LEPAUMIER, H. et CHANCEREL, A., 2006 - Les bracelets en pierre découverts en Basse-Normandie, bilan d'un inventaire. Archéologie et prospection en Basse-Normandie. Caen, Société des Antiquaires de Normandie (Mémoire XXXVIII), p. 117 136.

LEPAUMIER, H., MARCIGNY, C., CLÉMENT-SAULEAU, S. et GHESQUIÈRE, E., 2007 - Histoire et déboires d'un mégalithe : l'exemple du monument de la Hogue à Fontenayle-Marmion (Calvados). Un siècle de construction du discours scientifique en préhistoire. Paris, Société préhistorique française (Actes du XXVI ${ }^{\text {e }}$ Congrès préhistorique de France, Avignon, 2004), vol. 2, p. 249-264.

LESPEZ, L., 2007 avec la coll. de CLET-PELLERIN, M., Comment retrouver les paysages du Néolithique?. In, MARCIGNY, C., GHESQUIÈRE, E. et DESLOGES, J. (dir.), La hache et la meule : les premiers paysans du Néolithique en Normandie (catalogue d'exposition). Le Havre, éditions du Muséum d'Histoire naturelle du Havre, p. 34-41.

MARCIGNY, C., GHESQUIÈRE, E. et LEPAUMIER, H., 2006 - Un exemple de prospection thématique : l'inventaire des mégalithes de Basse-Normandie, l'exemple d'un polissoir inédit à Saint-Germain-de-Clairefeuille (Orne). Archéologie et prospection en Basse-Normandie. Caen, Société des Antiquaires de Normandie (Mémoire XXXVIII), p. 113-116.

MARCIGNY, C., 2007 - La Normandie au Néolithique. In, MARCIGNY, C., GHESQUIÈRE, E. et DESLOGES, J. (dir.), La hache et la meule : les premiers paysans du Néolithique en Normandie (catalogue d'exposition). Le Havre, éditions du Muséum d'Histoire naturelle du Havre, p. 19-23.

MARCIGNY, C., 2007 - Hommes ou Dieux figés dans la pierre : les menhirs. In, MARCIGNY, C., GHESQUIÈRE, E. et 
DESLOGES, J. (dir.), La hache et la meule : les premiers paysans du Néolithique en Normandie (catalogue d'exposition). Le Havre, éditions du Muséum d'Histoire naturelle du Havre, p. 149.

MARCIGNY, C., DESLOGES, J. et GHESQUIÈRE, E., 2007 - De la mine à la hache : les minières de silex de Ri-Ronai. In, DELRIEU, F. et DESLOGES, J. (dir.) avec la coll. de QUÉVILLON, S., ArchéOrne : 250 ans d'archéologie dans l'Orne (catalogue d'exposition). Cabourg, éditions Cahiers du temps, p. 50-51.

MARCIGNY, C., GHESQUIÈRE, E., CLÉMENT-SAULEAU, S., GAUMÉ, E., GIAZZON, D. et AUBRY, B., 2007 Premières occupations néolithiques dans le sud de l'Orne et le nord de la Sarthe. In, AGOGUE, O., LEROY, D. et VERJUX, C. (dir.), Camps, enceintes et structures d'habitat néolithiques en France septentrionale (Actes du $24^{\mathrm{e}}$ colloque interrégional sur le Néolithique, Orléans 1999). Revue Archéologique du Centre de la France, suppl. 27, p. 95-114.

MARCIGNY, C., GHESQUIÈRE, E. et GIAZZON, D., 2007 - Une grande enceinte à Goulet. In, DELRIEU, F. et DESLOGES, J. (dir.) avec la coll. De QUÉVILLON, S., ArchéOrne : 250 ans d'archéologie dans l'Orne (catalogue d'exposition). Cabourg, éditions Cahiers du temps, p. 58.

PROST, D., 2007 - La circulation des poignards pressigniens. MARCIGNY, C., GHESQUIÈRE, E. et DESLOGES, J. (dir.), La hache et la meule : les premiers paysans du Néolithique en Normandie (catalogue d'exposition). Le Havre, éditions du Muséum d'Histoire naturelle du Havre, p. 124-127.

SALLES, O., 2006 - Note sur des découvertes préhistoriques dans la partie normande du département de l'Orne. Archéologie et prospection en Basse-Normandie. Caen, Mémoires de la Société des Antiquaires de Normandie (Mémoire XXXVIII), p. 13-30.

SAN JUAN, G., GHESQUIÈRE, E., FONTUGNE, M., FROMONT, N. et GALLOUIN, E., 2007 - Une enceinte fortifiée du troisième millénaire avant J.-C. à Basly dans le Calvados : résultats préliminaires. In, AGOGUE, O., LEROY, D. et VERJUX, C. (dir.), 2007, Camps, enceintes et structures d'habitat néolithiques en France septentrionale (Actes du 24e colloque interrégional sur le Néolithique, Orléans 1999). Revue archéologique du Centre de la France, suppl. 27, p. 327-348.

VERRON, G., 2007 - Un monument funéraire complexe du Néolithique moyen à Vierville. In, MARCIGNY, C., GHESQUIÈRE, E. et DESLOGES, J. (dir.), La hache et la meule : les premiers paysans du Néolithique en Normandie (catalogue d'exposition). Le Havre, éditions du Muséum d'Histoire naturelle du Havre, p. 139-142.

\section{4. ÂGES DES MÉTAUX}

BAUDRY, A., 2007 - L'élevage et l'alimentation à la fin de l'âge du Bronze et au premier âge du Fer dans l'Ouest de la
France. Approche archéozoologique de quelques sites normands. Bulletin de l'APRAB (Association pour la Promotion des Recherches sur l'Âge du Bronze), 4, p. 45-46.

BERNOUIS, P. et SAN JUAN, G., 2006 - Les fortifications protohistoriques de relief dans le département du Calvados, inventaire actualisé. Archéologie et prospection en Basse-Normandie. Caen, Mémoires de la Société des Antiquaires de Normandie (Mémoire XXXVIII), p. 137-177.

BESNARD-VAUTERIN, C.-C., CHANCEREL, A. et MARCIGNY, C., 2006 - L'enceinte de l'âge du Bronze moyen de l'Etoile (Mondeville). In, CHANCEREL, A., MARCIGNY, C. et GHESQUIÈRE, E. (dir.), Le plateau de Mondeville (Calvados) du Néolithique à l'àge du Bronze. Paris: Maison des Sciences de l'Homme (Documents d'Archéologie française, 99), p. 111-138.

BESNARD-VAUTERIN, C.-C., 2007 - Une ferme de la fin de l'époque gauloise à Neuville-près-Sées, "Les Ruisseaux ». In, DELRIEU, F. et DESLOGES, J. (dir.) avec la coll. De QUÉVILLON, S., ArchéOrne : 250 ans d'archéologie dans l'Orne (catalogue d'exposition). Cabourg, éditions Cahiers du temps, p. 74-75.

BESNARD-VAUTERIN, C.-C., 2007 avec la coll. de BESNARD, M., CORDE, D. et FERET, L. - Un habitat de la fin de la période gauloise et un sanctuaire du Haut-Empire à Nécy (Orne) "La Martinière ": présentation liminaire. Bulletin de la Société historique et archéologique de l'Orne, 126 (n' 3-4), p. 117-128.

BILLARD, C et BERNARD, V., 2007 - Archéologie des pêcheries sur le littoral du département de la Manche. Bulletin du Groupe de Recherches archéologiques du Cotentin, 12, p. 28-29.

BRUN, P., GHESQUIÈRE, E. et MARCIGNY, C., 2007 - Le dépôt de casques de Bernières d'Ailly (Calvados) et la fonction sociale de l'armement défensif du XIv ${ }^{\mathrm{e}}$ au vi ${ }^{\mathrm{e}} \mathrm{s}$. av. J.-C. bulletin de l'APRAB (Association pour la promotion des recherches sur l'âge du Bronze), 4, p. 41.

CAROZZA, L. et MARCIGNY, C., 2007 - L'âge du Bronze en France. Paris, La Découverte, $155 \mathrm{p}$.

CARPENTIER, V., 2006 avec la coll. de LE GAILLARD, L. et MARCIGNY, C. - Un souterrain laténien dans son contexte à Cormelles-le-Royal (Calvados). Archéologie et prospection en Basse-Normandie. Caen, Mémoires de la Société des Antiquaires de Normandie (Mémoire XXXVIII), p. 209-218.

CARPENTIER, V., GHESQUIÈRE, E. et MARCIGNY, C., 2006 - Grains de sel, sel et salines de Normandie (préhistoire$\mathrm{XIX}^{\mathrm{e}}$ siècle), entre archéologie et histoire. Les Dossiers $d u$ Centre de Recherches et d'Archéologie d'Alet, $\mathbf{n}^{\circ}$ spécial, 182 p.

CARPENTIER, V., DUCLOS, C., GHESQUIÈRE, E., JEANNE, L., JOLIVET, P.-Y., LE GAILLARD, L. et MARCIGNY, C., 2006 - Un atelier de bouilleur de sel gaulois (120 à 58 av. J.-C.), éléments d'histoire fermanvillaise. Bulletin municipal de Fermanville, 2006, p. 30-31. 
CHANCEREL, A., MARCIGNY, C. et SAN JUAN, G., 2006 - La double enceinte de l'âge du Bronze moyen de la ZI Sud (Mondeville, Grentheville). In, CHANCEREL, A., MARCIGNY, C. et GHESQUIẼRE, E. (dir.), Le plateau de Mondeville (Calvados) du Néolithique à l'âge du Bronze. Paris, Maison des Sciences de l'Homme (Documents d'Archéologie française, 99), p. 139-172.

DELESTRÉE, P.-L. et WÉROCHWSKI, S., 2006 - Une série gauloise en or originale, aux confins de la Normandie et de l'Armorique. Cahiers Numismatiques, 169, p. 5-9.

DELRIEU, F., 2007 - Âges des métaux : le temps du métal, de l'agriculture et des fortifications. In, DELRIEU, F. et DESLOGES, J. (dir.) avec la coll. de QUÉVILLON, S., ArchéOrne : 250 ans d'archéologie dans l'Orne (catalogue d'exposition). Cabourg, éditions Cahiers du temps, p. 65-93.

DELRIEU, F., 2007 - Le camp de Bierre à Merri (Orne) : une fortification de la fin du $1^{\text {er }}$ âge du Fer. Bulletin de l'Association française pour l'Étude de l'Âge du Fer, 25, p. 5-8.

DELRIEU, F., 2007 - Le site du Camp de Bierre à Merri (Orne). Bulletin de la Société historique et archéologique de l'Orne, 126 (n' 3-4), p. 79-105.

DELRIEU, F., 2008 - Les tumulus de la presqu'ïle de la Hague. In, MARCIGNY, C. (dir.), Archéologie, Histoire et Anthropologie de la presquïle de la Hague (Manche) : analyse sur la longue durée d'un espace naturel et social cohérent. Troisième année de recherche, 2007 (rapport de PCR). Beaumont-Hague, Le Tourp, p. 41-61.

DELRIEU, F., 2008.- Présentation du PCR sur les sites fortifiés protohistoriques de hauteur de Basse-Normandie. Bulletin de l'Association française pour l'Étude de l'Âge du Fer, 26, p. 2122.

GALLOUIN, E., GHESQUIÈRE, E. et MARCIGNY, C., 2007 - Exmes : cité gauloise?. In, DELRIEU, F. et DESLOGES, J. (dir.) avec la coll. De QUÉVILLON, S., ArchéOrne : 250 ans d'archéologie dans l'Orne (catalogue d'exposition). Cabourg, éditions Cahiers du temps, p. 77.

GERMAIN-VALLÉE, C., 2007 - Une enceinte de plaine du Hallstatt D à Saint-Martin-de-Fontenay (14). Bulletin de l'Association française pour l'Étude de l'Âge du Fer, 25, p. 25-26.

GERMAIN-VALLÉE, C., 2007 avec la coll. de GIRAUD, P. et DURAND, R. - L'enclos funéraire de l'âge du Bronze de SaintMartin-de-Fontenay (Calvados, Basse-Normandie). Bulletin de la Société préhistorique française, 104 ( $\mathbf{n}^{\circ}$ 3), p. 565-581.

GIRAUD, P., 2007 - L'oppidum du «Castellier " à Saint-Désir/ Saint-Pierre-des-Ifs (14). Bulletin de l'Association française pour l'Étude de l'Âge du Fer, 25, p. 21-24.

GIRAUD, P., 2007 - Fontenay-le-Marmion "La Grande Pièce ". L'occupation de l'âge du Bronze. Bulletin de l'APRAB (Association pour la promotion des recherches sur l'àge du Bronze), 4, p. 16-17.
GIRAUD, P., RIQUIER, C., BAUDRY, A. et GAUDIN, L., 2007 - L'habitat Bronze final/Hallstatt ancien de « la Grande Pièce " à Fontenay-le-Marmion (Calvados). bulletin de l'APRAB (Association pour la promotion des recherches sur l'âge du Bronze), 4, p. 46-47.

GUILLAUMET, J.-P., 2006 - Quelques autres dépôts d'Europe [Trelly (Manche)]. In, BATAILLE, G. et GUILLAUMET, J.P. (dir.), Les dépôts métalliques au second âge du Fer en Europe tempérée (Actes de la table ronde de Bibracte, 2004). Gluxen-Glenne, Bibracte, Centre archéologique européen, coll. Bibracte, 11, p. 183-190.

HINCKER, V., 2007 - Les fermes protohistoriques et antiques de Buré. In, DELRIEU, F. et DESLOGES, J. (dir.) avec la coll. De QUÉVILLON, S., ArchéOrne : 250 ans d'archéologie dans l'Orne (catalogue d'exposition). Cabourg, éditions Cahiers du temps, p. 76.

JEANNE, L., LE GAILLARD, L., CARPENTIER, V., DUCLOS, C., GHESQUIÈRE, E. et MARCIGNY, C., 2007 - Un atelier de bouilleur de sel gaulois (-120/-58 av. J. C). Bulletin du Groupe de Recherches archéologiques du Cotentin, 12, p. 3031.

LE GOFF, E., AUXIETTE, G. et LE GOFF, I., 2007 avec la coll. de BOULESTIN, B., CHEREL, A.-F. et PILETLEMIERE, J. - Manifestations et pratiques cultuelles au sein des habitats et du territoire laténien de la "ZAC Object'Ifs Sud" à Ifs (Calvados) : un exemple de l'ouest de la Gaule. L'âge du Fer dans l'arc jurassien et ses marges : dépôts, lieux sacrés et territorialité à l'âge du Fer (Actes du $29^{\mathrm{e}}$ colloque international de l'Association française pour l'Étude de l'Âge du Fer, Bienne 2005). Besançon : Annales littéraires de l'Université de Franche-Comté, vol. 2, p. 579-584.

LEPAUMIER, H., 2007 - Cerisé " parc d'activité " : une nécropole tumulaire des âges des métaux. In, DELRIEU, F. et DESLOGES, J. (dir.) avec la coll. de QUÉVILLON, S., ArchéOrne : 250 ans d'archéologie dans l'Orne (catalogue d'exposition). Cabourg, éditions Cahiers du temps, p. 88-89.

LEPAUMIER, H., 2007 - Cerisé (61), parc d'activité. Une nécropole tumulaire en périphérie alençonnaise. bulletin de l'APRAB (Association pour la promotion des recherches sur l'âge du Bronze), 4, p. 24-25.

LEPAUMIER, H., CHANSON, K. et GIAZZON, D., 2007 - La tombe à char d'Orval. Archéopages, 19, p. 14-15.

LEPAUMIER, H., CHANSON, K. et GIAZZON, D., 2007 Orval (Manche) «Les Pleines ». Une tombe à char de la fin de La Tène ancienne, présentation préliminaire. Bulletin de l'Association française pour l'Étude de l'Âge du Fer, 25, p. 68-70.

LORHO, T., BLANCQUAERT, G. et MALRAIN, F., 2007 - Un inventaire national des sites ruraux du Hallstatt D3 au Galloromain précoce. Bulletin de l'Association française pour l'Étude de l'Âge du Fer, 25, p. 41-47. 
MARCIGNY, C., 2006 - Les structures du Bronze final et du premier âge du Fer de la Delle Saint-Martin (Mondeville). In, CHANCEREL, A., MARCIGNY, C. et GHESQUIÈRE, E. (dir.), Le plateau de Mondeville (Calvados) du Néolithique à l'âge du Bronze. Paris, Maison des Sciences de l'Homme (Documents d'Archéologie française, 99), p. 173-179.

MARCIGNY, C., GHESQUIÈRE, E., FROMONT, N., BESNARD-VAUTERIN, C.C., CLÉMENT-SAULEAU, S., JEANNE, L., GALLOUIN, E., JUHEL, L. et NOËL, J.-Y., 2006 - Habitats et pratiques funéraires et cultuelles de l'âge du Bronze en Normandie, bilan des travaux 2005. Bulletin de l'APRAB (Association pour la promotion des recherches sur l'âge du Bronze), 3, p. 78-83.

MARCIGNY, C., 2007 - L'apport des sites du département de la Manche au programme collectif de recherche « Habitats et occupation du territoire à l'âge du Bronze et au début du premier âge du Fer en Basse-Normandie ». Bulletin du Groupe de Recherches archéologiques du Cotentin, 12, p. 22-23.

MARCIGNY, C., CARPENTIER, V. et GHESQUIÈRE, E., 2007 - La presqu'île de la Hague à l'âge du Bronze : le "Hague Dike ». Bulletin du Groupe de Recherches archéologiques du Cotentin, 12, p. 24-27.

MARCIGNY, C. et GHESQUIÈRE, E., 2007 - L'âge du Bronze en Basse-Normandie. Bilan des travaux 2006. Bulletin de l'APRAB (Association pour la promotion des recherches sur l'âge du Bronze), 4, p. 74-76.

MARCIGNY, C., GHESQUIÈRE, E. et KINNES, I., 2007 Bronze Age Cross-Channel Relations. The Lower-Normandy (France) example : Ceramic Chronology and First Reflections. In, BURGESS, C., TOPPING, P. and LYNCH, F. (ed.), Beyond Stonehenge. Essays on the Bronze Age in honour of Colin Burgess. Oxford, Oxbow Books, p. 255-267.

MARCIGNY, C. et TALON, M., 2007 - De la Normandie aux Flandres, qu'en est-il du passage de l'âge du Bronze à l'âge du Fer?. Bulletin de l'APRAB (Association pour la promotion des recherches sur l'âge du Bronze), 4, p. 39-40.

NILLESSE, O., 2006 - Les dépôts d'objets en fer dans les établissements ruraux gaulois de l'ouest de la France : le rituel est-il au fond de la poubelle?. In, BATAILLE, G. et GUILLAUMET, J.-P. (dir.), Les dépôts métalliques au second âge du Fer en Europe tempérée (Actes de la table ronde de Bibracte, 2004). In, Gluxen-Glenne, Bibracte, Centre archéologique européen, coll. Bibracte, 11, p. 221-246.

NOËL, J.-Y., 2006 - Entre nouvelles perspectives et restrictions : l'occupation campaniforme de Digulleville. In, MARCIGNY, C. (dir), 2006, Archéologie, Histoire et Anthropologie de la Presqu'ile de la Hague (Manche) : analyse sur la longue durée d'un espace naturel et social cohérent. (Deuxième année de recherche, rapport de PCR) Beaumont-Hague, Le Tourp, p. 34-39.

NOËL, J.-Y. et SALANOVA, L., 2007 - Les campaniformes en Normandie: nouvelle symbolique et premiers métaux. In,
MARCIGNY, C., GHESQUIÈRE, E. et DESLOGES, J. (dir.), La hache et la meule : les premiers paysans du Néolithique en Normandie (catalogie d'exposition). Le Havre, éditions du Muséum d'Histoire naturelle, p. 170-177.

OUDRY, S., 2007 - Les inhumations de la nécropole Hallstatt final de Basly (Calvados), approche biologique et sociale. Revue Archéologique de l'Ouest, 24, p. 73-87.

SERVAT, J., 2007 - Tombe à char à Orval (Manche). L'Archéologue, archéologie nouvelle, $\mathbf{9 0}$, p. 48-49.

VAN DEN BOSSCHE, B., 2007 - Le mobilier céramique du Bronze final et du début du premier âge du Fer du MontJoly à Soumont-Saint-Quentin (Calvados) : nouvelles données. Bulletin de la Société préhistorique française, $104\left(\mathbf{n}^{\circ} \mathbf{1}\right)$, p. 147-170.

VERNIOLES, J., 2007 - Quelques nouvelles données sur les sites vitrifiés en France. Bulletin de l'Association française pour l'Étude de l'Âge du Fer, 25, p. 37-39.

\section{Gaule romaine}

BAUDRY, A., 2007 - La faune de l'établissement rural antique de Sées «Le Grand Herbage "(Orne). Revue Archéologique de l'Ouest, 24, 2007, p. 191-201.

BYHET, T., 2007 - Contribution à l'étude des portiques de rue dans les villes du nord de la Gaule. In, HANOUNE, R. (dir.), Les Villes romaines du nord de la Gaule. Revue du Nord, Horssérie (coll. Art et archéologie n 10), p. 422-446.

DEMAREST, M., 2007 - Le mobilier métallique découvert sur le site antique de Sées "Le Grand Herbage " (Orne). Revue Archéologique de l'Ouest, 24, p. 169-189.

DUMASY, F., 2007 - Les édifices de spectacle en Gaule du nord. De la typologie à la chronologie. In, HANOUNE, R. (dir.) - Les Villes romaines du nord de la Gaule. Revue du Nord, Horssérie (coll. Art et archéologie n 10), p. 447-465.

FICHET DE CLAIRFONTAINE, F. et LECLERC, G., 2007 - Antiquité : L'Orne gallo-romaine. In, DELRIEU, F. et DESLOGES, J. (dir.), avec la coll. de QUÉVILLON, S., ArchéOrne : 250 ans d'archéologie dans l'Orne (catalogue d'exposition). Cabourg, éditions Cahiers du temps, p. 94-115.

JEANNE, L., 2007 - Les traces d'une villa gallo-romaine à Benoitville : sondages archéologiques. Bulletin du Groupe de Recherches archéologiques du Cotentin, 2007, p. 34-35.

JEANNE, L., DUCLOS, C. et LE GAILLARD, L., 2007 - Un établissement rural des $\mathrm{I}^{\text {er }}$ et II $^{\mathrm{e}}$ siècles : le hameau Valognes à Brillevast. Bulletin du Groupe de Recherches archéologiques du Cotentin, 12, p. 32-34.

LE GAILLARD, L., 2007 - La villa gallo-romaine de Marcéi : premier aperçu par les travaux autoroutiers. Bulletin de la Société historique et archéologique de l'Orne, 126 ( $\mathbf{n}^{\circ}$ 3-4), p. 147-157. 
LE GAILLARD, L. et ZAOUR, N., 2007 - Extraction et réduction du minerai de fer au Ier siècle après J.-C. à Sées : diagnostic archéologique dans l'enceinte de l'Hôpital Local. Bulletin de la Société historique et archéologique de l'Orne, 126 (n³-4), p. 159-186.

LECLERC, G., 2006 - Les apports de la prospection archéologique à la connaissance du peuplement antique de l'Orne. Archéologie et prospection en Basse-Normandie. Caen, Société des Antiquaires de Normandie (Mémoire XXXVIII), p. 180186.

LECLERC, G., 2007 - Les sanctuaires complexes en Gaule Romaine : l'originalité du site de Macé (Orne). Bulletin de la Société historique et archéologique de l'Orne, 126 (nº 3-4), p. 129-145.

LECLERC, G., 2007 - L'établissement rural antique du Grand Herbage à Sées (Orne). Revue archéologique de l'Ouest, 24, p. 139-167.

LEJARS, T. et PERNET, L., 2007 - Le sanctuaire d'Aunou-surOrne. In, DELRIEU, F. et DESLOGES, J. (dir.), avec la coll. de QUÉVILLON, S., ArchéOrne : 250 ans d'archéologie dans l'Orne (catalogue d'exposition). Cabourg, éditions Cahiers du temps, p. 92-93.

LEJARS, T. et PERNET, L., 2007 - Le gisement protohistorique et gallo-romain du «Pré du Mesnil » à Aunou-sur-Orne : un site à caractère cultuel. Bulletin de la Société historique et archéologique de l'Orne, 126 (n 3-4), p. 107-116.

LEPELLEY, R., 2006 - Les toponymes gaulois du passage de l'eau en Normandie : Rouen et les autres. Annales de Normandie, $56^{\mathrm{e}}$ année, 4, p. 451-461.

LEVALET, D., 2006 - Le Repas (Manche) : une station routière gallo-romaine?. Annales de Normandie, 56 année, 1, p. 3-28.

PAEZ-REZENDE, L., DUCLOS, C., JEANNE, L. et LE GAILLARD, L., 2007 - L'agglomération secondaire de Montaigu-la-Brisette. Bulletin du Groupe de Recherches archéologiques du Cotentin, 12, p. 36-38.

PAILlARD, D., ALDUC-LE AGOUSSE, A., BUCHET, L., BLONDIAUX, J. et NIEL, C., 2008 - Identité sociale ou miroir d'une société en évolution? Les tombes remarquables de la seconde moitié du IV ${ }^{\mathrm{e}}$ siècle dans la nécropole Michelet à Lisieux (Calvados). Inhumations de prestige ou prestige de l'inhumation. Expressions du pouvoir dans l'au-delà (Première table ronde du Cinquantenaire du CRAHM, Caen, 2007), Caen, Publications du CRAHM, 2008.

QUÉVILLON, S., 2007 - Apparition du phénomène urbain : Sées antique. In, DELRIEU, F. et DESLOGES, J. (dir.), avec la coll. de QUÉVILLON, S., ArchéOrne : 250 ans d'archéologie dans l'Orne (catalogue d'exposition). Cabourg, éditions Cahiers du temps, p. 100-101.

QUÉVILLON, S., 2007 - Un atelier paléométallurgique à SaintEvroult-de-Montfort. In, DELRIEU, F. et DESLOGES, J. (dir.), avec la coll. De QUÉVILLON, S., ArchéOrne : 250 ans d'archéologie dans l'Orne (catalogue d'exposition). Cabourg, éditions Cahiers du temps, p. 115.

VIPARD, P., 2007 - Maison à péristyle et élites urbaines en Gaule sous l'Empire. Gallia, 64, p. 227-277.

\section{6. ÉPOQUe MÉDIÉVALE}

ALEXANDRE-BIDON, D., PIPONNIER, F. et POISSON, J.-M. (dir.), 2006 - Cadre de vie et manières d'habiter (XII $X V T^{e}$ siècles). Actes du VIII ${ }^{\mathrm{e}}$ Congrès international de la Société d'Archéologie médiévale (Paris 2001). Caen, Publications du CRAHM, $328 \mathrm{p}$.

BAUME, A., 2007 - Le document et le terrain : le tracé du système défensif normand au XII ${ }^{\mathrm{e}}$ siècle. In, FLAMBARDHERICHER, A.-M. et GAZEAU, V. (dir.), 2007, La Normandie entre Plantagenêts et Capétiens. Caen, Publications du CRAHM, p. 93-112.

BAYLÉ, M., 2007 - L'église de Saint-Cénéri-le-Gerei. Art de BasseNormandie, 134, p. 18-21.

BECK, B, LEROUX, P., LEVESQUE, J.-M. et MARIN, J.-Y., 2007 - Donjons et forteresses : voyage dans la Normandie médiévale. Au fil de la Normandie, 15, p. 18-39.

BERNAGE, G., 2006 - Demeures et châteaux en Normandie au $\mathrm{XI}^{\mathrm{e}}$ siècle. Patrimoine normand, 56, 2006, p. 28-33.

BERNAGE, G., 2006 - Découverte d'un manoir du XIII ${ }^{\mathrm{e}}$ siècle à Damigny. Patrimoine normand, 57, 2006, p. 44-48.

BERNAGE, G., 2007 - Journées du patrimoine : l'abbaye de Longues. Patrimoine normand, 64, p. 42-47.

BERNAGE, G., 2007 - Le prieuré de Saint-Arnoul-sur-Touque. Patrimoine normand, 64, p. 30-35.

BUTTITTA, et MARIN, J.-Y. (dir.), 2006 - Les Normands en Sicile, $X I^{e}-X X I^{e}$ siècles. Histoire et légendes. (catalogue d'exposition). Caen, Musée de Normandie, 175 p.

CAILLEUX, P., 2007 - Le développement urbain de la capitale normande entre Plantagenêts et Capétiens. In, FLAMBARDHERICHER, A.-M. et GAZEAU, V. (dir.), La Normandie entre Plantagenêts et Capétiens. Caen, Publications du CRAHM, p. 261-274.

CARPENTIER, V., 2006 - Eterville (Calvados). Les Marronniers. Chronique des fouilles médiévales en France en 2005. Archéologie médiévale, 36, p. 253.

CARPENTIER, V. et HINCKER, V., 2006 - L'habitat rural du haut Moyen Âge en Basse-Normandie : bilan de vingt années de recherches archéologiques régionales. Bulletin de liaison de l'Association française d'Archéologie mérovingienne, 30 (XXVII ${ }^{\mathrm{e}}$ journées internationales d'Archéologie mérovingienne, Caen 2006), p. 75.

CARPENTIER, V., 2007 - Images antiques, médiévales et modernes de la consommation des produits de la mer : quelques données récentes en Basse-Normandie. In, RIDEL, E., BARRÉ, 
E. et ZYSBERG, A. (dir.), 2007, Les nourritures de la mer, de la criée à l'assiette : techniques de conservation, commerce et pratiques alimentaires des produits de la mer, de l'Antiquité à nos jours. (Actes du colloque de Tatihou, 2003). Caen, Centre de Recherche d'Histoire quantitative (coll. Histoire maritime, 4), p. 57-75.

CARPENTIER, V., 2007 - La fouille et l'histoire : apports récents de l'archéologie à l'histoire de l'habitat rural du haut Moyen Âge en Basse-Normandie. In, MADELINE P., MORICEAU J.-M. (dir.), Bâtir dans les campagnes. Les enjeux de la construction de la Protohistoire au XXI siècle. Caen, Presses universitaires de Caen, MRSH, 2007, p. 153-168. (Bibliothèque du pôle rural, $n^{\circ}$ hors-série des Enquêtes rurales).

CARPENTIER, V., 2007 - Le site de Plomb "Le Mesnil » (Manche), IX ${ }^{\mathrm{e}}-\mathrm{XII}^{\mathrm{e}}$ siècles : regard sur l'habitat rural du haut Moyen Âge dans l'ouest français. Archéologie médiévale, 37, p. 1-52.

CARPENTIER, V., FAJAL, B. et FOUCHER, J.-P., 2008 - La gestion des ressources piscicoles d'une abbaye normande au $\mathrm{XIII}^{\mathrm{e}}$ siècle d'après un registre d'exploitation inédit. Archéologie du poisson, exploitations et impacts, transformations et usages, paléoenvironnements, 30 ans d'Archéo-ichtyologie au CNRS (Actes des XXVIII ${ }^{e}$ rencontres internationales d'Archéologie et d'Histoire d'Antibes). Antibes, APCDA, p. 91-99.

CARRÉ, G., 2007 - La Hoguette (Calvados) : ancienne abbaye Saint-André-en-Gouffern. Chroniques des fouilles médiévales en France en 2006. Archéologie médiévale, 37, p. 227.

CLAVEL, B. et FRÈRE, S., 2007 - Étude archéozoologique de deux implantations rurales sur le littoral français au Moyen Âge. Archéopages, 18, p. 52-57.

CORVISIER, C., 2007 - Le château de Condé-sur-Noireau : actes du $165^{\mathrm{e}}$ congrès de l'Association normande pour les progrès de l'agriculture, de l'industrie, des sciences et des arts, Condé-sur-Noireau, 2007. Annuaire des cinq départements de la Normandie, p. 28-36.

DELAHAYE, F., 2007 - Blay (Calvados) : le Castel. Chroniques des fouilles médiévales en France en 2006. Archéologie médiévale, 37, p. 253.

DELAHAYE, F. et NIEL, C., 2007 - Thaon : église Saint-Pierre (Calvados). Chroniques des fouilles médiévales en France en 2006. Archéologie médiévale, 37, p. 245-246.

DELAHAYE, F., NIEL, C., ALDUC-LE BAGOUSSE, A. et BLONDIAUX, J., 2008 - L'église Saint Pierre de Thaon (Calvados) : premières approches archéologiques et anthropologiques. La paroisse en Normandie au Moyen Âge, La vie paroissiale, l'église et le cimetière, Histoire - art-archéologie. (Actes du colloque de Saint Lô, 2002). Saint-Lô, Société d'Archéologie et d'Histoire de la Manche (Études et documents, 27), p. 332-354.

DESFORGES, J.-D., 2006 - La nécropole du Mont-Romigny (Saint-Hilaire/Sainte-Céronne, Orne). Évaluation 2006.
Bulletin de liaison de l'Association française d'Archéologie mérovingienne, 30 (XXVII ${ }^{\mathrm{e}}$ journées internationales d'Archéologie mérovingienne, Caen 2006), p. 95-96.

DESFORGES, J.-D., 2007 - Archéologie du bâti : la Maison des Sept Colonnes (Alençon, Orne). Bulletin de la Société historique et archéologique de l'Orne, 126 (n 3-4), p. 187-198.

DESFORGES, J.-D. et MORAND, F., 2007 - Aux origines de Mortagne-au-Perche : la butte Saint-Malo. Cahiers percherons, 171 , p. $29-40$.

DESHAYES, J., 2007 - L'église paroissiale Notre Dame à Brévands. Bulletin du Groupe de Recherches archéologiques du Cotentin, 12, p. 39-40.

DESHAYES, J. et VILGRAIN-BAZIN, G., 2008 - L'église SaintGilles à Auderville. In, MARCIGNY, C. (dir.), Archéologie, Histoire et Anthropologie de la presquïle de la Hague (Manche) : analyse sur la longue durée d'un espace naturel et social cohérent. Troisième année de recherche, 2007 (rapport de PCR). Beaumont-Hague, Le Tourp, p. 72-77.

DUCOEUR, D., 2007 - Les moulins de l'abbaye de La Lucerne. Revue de l'Avranchin et du Pays de Granville, 84 (fasc. 412), p. 223-292.

EFFROS, B., 2006 - Arcisse de Caumont et la professionnalisation de l'archéologie du haut Moyen Âge en France. Bulletin de liaison de l'Association française d'Archéologie mérovingienne, 30 (XXVII $^{\mathrm{e}}$ journées internationales d'Archéologie mérovingienne, Caen 2006), p. 73.

EPAUD, F., 2007 - De la charpente romane à la charpente gothique en Normandie. Caen, Publications du CRAHM, 613 p.

FAJAL, B., 2006 - À partir de sites médiévaux inédits, quelques remarques sur le repérage d'ateliers de potiers en BasseNormandie. Archéologie et prospection en Basse-Normandie. Caen, Société des Antiquaires de Normandie, 2006, (Mémoire XXXVIII), p. 187-195.

FAJAL, B., 2008 - Nouvelles données sur l'atelier de potier médiéval d'Argentan [Michel de Boüard, 1966]. Argentan et ses environs au Moyen Âge, approche archéologique et historique. Alençon, Conseil général de L’Orne, p. 247-258.

FICHET de CLAIRFONTAINE, F. et DUFOURNIER, D., 2006 - La maison du potier du XI ${ }^{\mathrm{e}}$ au XVII ${ }^{\mathrm{e}}$ siècle dans la France du nord-ouest. In, ALEXANDRE-BIDON, D., PIPONNIER, F. et POISSON, J.-M. (dir.), Cadre de vie et manières d'habiter (XII'-XVI siècles). Actes du VIII ${ }^{e}$ Congrès international de la Société d'Archéologie médiévale (Paris 2001). Caen, Publications du CRAHM, p. 267-273.

FICHET DE CLAIFONTAINE, F., FLAMBARD-HÉRICHER, A.-M. et FAJAL, B., 2007 - Témoins du Moyen Âge : L'Orne médiévale. In, DELRIEU, F. et DESLOGES, J. (dir.), avec la coll. De QUÉVILLON, S., ArchéOrne : 250 ans d'archéologie dans l'Orne (catalogue d'exposition). Cabourg, éditions Cahiers du temps, p. 117-139. 
FLAMBARD-HÉRICHER, A.-M., 2006 - La Pommeraye (Calvados). Château Ganne. Chronique des fouilles médiévales en France en 2005. Archéologie médiévale, 36, p. 310-312.

FLAMBARD-HÉRICHER, A.-M., 2006 (dir.) - Les lieux de pouvoir au Moyen Âge en Normandie et sur ses marges. (Tables-rondes du CRAHM, 2). Caen, Publications du CRAHM, 256 p.

FLAMBARD-HÉRICHER, A.-M., 2006 - Les seigneurs de la Pommeraie, le château Ganne et le peuplement du territoire de la Pommeraie - Saint-Omer (Cinglais, Normandie) au XII ${ }^{\mathrm{e}}$ siècle. In, ETTEL, P., FLAMBARD-HÉRICHER, A.-M. et Mc NEILL, T.-E. (dir.), 2006 - Château Gaillard, 22 (Château et peuplement : Actes du Colloque international de Voiron, 2004). p. 139-148.

FLAMBARD-HÉRICHER, A.-M., 2006 - Un habitat aristocratique percheron dans son environnement. La «Butte du Château " à Bretoncelles (Orne). In, ALEXANDRE-BIDON, D., PIPONNIER, F. et POISSON, J.-M. (dir.), Cadre de vie et manières d'habiter (XII $-X V I^{e}$ siècles). Actes du VIII ${ }^{\mathrm{e}}$ Congrès international de la Société d'Archéologie médiévale, Paris 2001. Caen, Publications du CRAHM, p. 275-281.

FLAMBARD-HÉRICHER, A.-M., 2007 - La "Butte du Château " à Bretoncelles. In, DELRIEU, F. et DESLOGES, J. (dir.), avec la coll. De QUÉVILLON, S., ArchéOrne : 250 ans d'archéologie dans l'Orne (catalogue d'exposition). Cabourg, éditions Cahiers du temps, p. 130-131.

FLAMBARD-HÉRICHER, A.-M., 2007 - La Pommeraye (Calvados) : Château Ganne. Chroniques des fouilles médiévales en France en 2006. Archéologie médiévale, 37, p. 266-268.

FLAMBARD-HÉRICHER, A.-M., 2007 - Le château Ganne à la Pommeraye (Calvados) : actes du $165^{\mathrm{e}}$ congrès de l'Association normande pour les progrès de l'agriculture, de l'industrie, des sciences et des arts. Condé-sur-Noireau, 2007. Annuaire des cinq départements de la Normandie, p. 127-154.

FLAMBARD-HERICHER, A.-M., 2008 - Le Château Ganne. Premiers résultats de la fouille archéologique. Caen, Publications du CRAHM (coll. Lieux communs), 128 p.

FLAMBARD-HERICHER, A.-M., 2008 - Le château Ganne à la Pommeraye (Calvados). Bilan des recherches 2004-2007 : actes du 165 e congrès de l'Association normande pour les progrès de l'agriculture, de l'industrie, des sciences et des arts. Condé-sur-Noireau : Association Normande, 2007. Annuaire des cinq départements de la Normandie, p. 127-154.

GUÉRIN, T., 2006 - Calvados. Sites fossoyés de la basse vallée de la Dives. Chronique des fouilles médiévales en France en 2005. Archéologie médiévale, 36, p. 319-322.

GUILLOT, B., 2006 - Caen (Calvados). Château, angle nordouest de la fortification. Chronique des fouilles médiévales en France en 2005. Archéologie médiévale, 36, p. 301-303.

HANACHI, S., 2006 - Basse-Normandie : sites fossoyés médiévaux. Chronique des fouilles médiévales en France en 2005. Archéologie médiévale, 36, p. 318-319.
HANACHI, S., 2007 - Basse-Normandie : sites fossoyés médiévaux. Chroniques des fouilles médiévales en France en 2006. Archéologie médiévale, 37, p. 278.

HANUSSE, C., 2006 - L'organisation des espaces de circulation dans l'habitat rural de la Plaine de Caen. L'exemple du site des Fosses Saint-Ursin (XIII ${ }^{\mathrm{e}}$-XIV ${ }^{\mathrm{e}}$ siècles). In, ALEXANDREBIDON, D., PIPONNIER, F. et POISSON, J.-M. (dir.), Cadre de vie et manières d'habiter (XIt-XVI siècles). Actes du VIII ${ }^{\mathrm{e}}$ Congrès international de la Société d'Archéologie médiévale, Paris 2001. Caen, Publications du CRAHM, p. 81-89.

HANUSSE, C., 2007 - Courseulles-sur-Mer (Calvados) : Fosses Saint-Ursin. Chroniques des fouilles médiévales en France en 2006. Archéologie médiévale, 37, p. 182-184.

HANUSSE, C. et JARRY, T., 2007 - Espace bâti et habitation en Normandie (Plaine de Caen) du XIII ${ }^{\mathrm{e}}$ au Xv $\mathrm{Xv}^{\mathrm{e}}$ siècle. Mise en regard des sources archéologiques et textuelles. In, MADELINE, P., MORICEAU, J.-M. (dir.), Bâtir dans les campagnes. Les enjeux de la construction de la Protohistoire au XXI siècle. Caen, Presses universitaires de Caen, MRSH, 2007, p. 133-152. (Bibliothèque du pôle rural, $\mathrm{n}^{\circ}$ hors-série des Enquêtes rurales).

HANUSSE, C. et TIXIER, B., 2008 - La paroisse disparue de Courtisigny au diocèse de Bayeux. Eléments d'enquête. $L a$ paroisse en Normandie au Moyen Âge, La vie paroissiale, l'église et le cimetière, Histoire - art-archéologie. (Actes du colloque de Saint Lô, 2002), Saint-Lô, Société d'Archéologie et d'Histoire de la Manche (Etudes et Documents, 27), p. 238-260.

HINCKER, V., 2006 - Evolution des corpus céramiques en usage au haut Moyen Âge en Basse-Normandie à travers l'étude des rejets domestiques en contexte rural. In, HINCKER, V. et HUSI, P. (dir.),- La céramique du haut Moyen Âge dans le nordouest de l'Europe ( $V^{e}-X^{e}$ siècles). Actes du colloque de Caen, 2004. Condé-sur-Noireau, Editions NEA, p. 131-157.

HINCKER, V., 2006- La nécropole mérovingienne de "SaintSauveur " de Manerbe (Calvados). Bulletin de liaison de l'Association française d'Archéologie mérovingienne, 30 (XXVII ${ }^{\mathrm{e}}$ journées internationales d'Archéologie mérovingienne, Caen 2006), p. 99-100.

HINCKER, V., 2006 - Manerbe (Calvados). Saint-Sauveur. Chronique des fouilles médiévales en France en 2005. Archéologie médiévale, 36, p. 281-282.

HINCKER, V. et HUSI, P. (dir.), 2006 - La céramique du haut Moyen $\hat{A}$ ge dans le nord-ouest de l'Europe ( $V^{\vee}-X^{e}$ siècles). Actes du colloque de Caen, 2004. Condé-sur-Noireau, Editions NEA, 429 p.

HINCKER, V., JARDEL, K., SAVARY, X. et DELACAMPAGNE, F., 2006 - Un atelier de potier carolingien à Subles et éléments de comparaison avec l'atelier de Verdun à Bayeux (Calvados). In, HINCKER, V. et HUSI, P. (dir.), 2006, La céramique du haut Moyen Âge dans le nord-ouest de l'Europe (V $V^{e}$ siècles). Actes du colloque de Caen, 2004. Condé-sur-Noireau, Editions NEA, p. 75-92. 
HINCKER, V., de SAINT-JORES, J.-X. et SAVARY, X., 2006

- Artisanat et échanges en Basse-Normandie à la période mérovingienne : l'apport de la fouille de l'habitat de Giberville (Calvados). Voies d'eau, commerce et artisanat en Gaule mérovingienne. (Actes du colloque de l'Association française d'Archéologie mérovingienne, Namur 1999). Namur, Ministère de la Région wallone, 2005 Etudes et documents, Archéologie, 10, p. 51-69.

HINCKER, V., 2007 - L'abbaye de Saint-Evroult. In, DELRIEU, F. et DESLOGES, J. (dir.), avec la coll. de QUÉVILLON, S., ArchéOrne : 250 ans d'archéologie dans l'Orne (catalogue d'exposition). Cabourg, éditions Cahiers du temps, p. 121.

HINCKER, V., 2007 - Manerbe (Calvados) : chapelle SaintSauveur. Chroniques des fouilles médiévales en France en 2006. Archéologie médiévale, 37, p. 295.

HINCKER, V., 2007 - Un habitat aristocratique en Neustrie : le site du château à Biéville-Beuville (Calvados, Normandie, France). In, VERSLYPE, L. (dir.), Villes et campagnes en Neustrie (Actes des XXV Journées internationales d'Archéologie mérovingienne). Montagnac : éditions M. Mergoil (coll. Europe médiévale, 8), p. 175-189.

HINCKER, V., 2007 - De la ville antique au village médiéval. Déclin de la capitale des Viducasses : Vieux (Calvados) du Iv ${ }^{\mathrm{e}}$ siècle à l'an Mil. Annales de Normandie, $57^{\mathrm{c}}$ année, 1-2, p. 326.

JUHEL, V., 2007 - Aperçu sur les anciennes voies de communication de la région de Condé-sur-Noireau : actes du $165^{\mathrm{e}}$ congrès de l'Association normande pour les progrès de l'agriculture, de l'industrie, des sciences et des arts, Condé-sur-Noireau, 2007. Annuaire des cinq départements de la Normandie, p. 7-12.

JUHEL, V., 2007 - Les peintures murales [Saint-Cénéri-le-Gerei]. Art de Basse-Normandie, $\mathrm{n}^{\circ} 134$, p. 24-37.

LABAUNE, J.-.F., 2007 - Une production d'enseignes de pèlerins au Mont-Saint-Michel. Archéopages, 18, p. 80-81.

LECCEUR, D., 2007 - L'enceinte fortifiée du Plessis-Grimoult : actes du $165^{\circ}$ congrès de l'Association normande pour les progrès de l'agriculture, de l'industrie, des sciences et des arts, Condé-sur-Noireau, 2007. Annuaire des cinq départements de la Normandie, p. 21-22.

LE GAILlARD, L., 2007 - Sées (Orne) : Hôpital local. Chroniques des fouilles médiévales en France en 2006. Archéologie médiévale, 37, p. 244.

GUEGAN, R., 2006 - La langue [viking] en héritage. Pays de Normandie, 54, p. 30-34.

LEGOUX, R., PÉRIN, P. et VALLET, F., 2006 - Chronologie normalisée du mobilier funéraire mérovingien entre Manche et Lorraine. Bulletin de liaison de l'Association française d'Archéologie mérovingienne, hors-série 2004, 61 p.

LELIEVRE, J.-Y., 2007 - Vieux (Calvados) : place du lavoir Saint-Martin. Chroniques des fouilles médiévales en France en 2006. Archéologie médiévale, 37, p. 301-302.
LE MAHO, J., 2006 - Fortifications et déplacements de populations en France au temps des invasions normandes ( $\left(\mathrm{x}^{\mathrm{e}}-\mathrm{X}^{\mathrm{e}}\right.$ siècles). In, ETTEL, P., FLAMBARD-HÉRICHER, A.-M. et Mc NEILL, T.-E. (dir.), 2006, Château Gaillard, 22 (Château et peuplement : Actes du Colloque international de Voiron, 2004). p. 223-236.

LÉON, C., 2007 - La forge du château de Caen au Moyen Âge d'après les sources écrites ( $\mathrm{xIV}^{\mathrm{e}}-\mathrm{XV}^{\mathrm{e}}$ siècles). Annales de Normandie, $57^{\mathrm{c}}$ année, 3-4, p. 231-248.

LEPETZ, S. et SCHNEIDER, M., 2007 - L'exploitation, la commercialisation des huitres à l'époque romaine en Gaule : des origines géographiques et sources d'approvisionnement des huitres du Vieil-Evreux et de Chartres. In, RIDEL, E., BARRÉ, E. et ZYSBERG, A. (dir.), Les nourritures de la mer, de la criée à l'assiette : techniques de conservation, commerce et pratiques alimentaires des produits de la mer, de l'Antiquité à nos jours. (Actes du colloque de Tatihou, 2003). Caen, Centre de Recherche d'Histoire quantitative (coll. Histoire maritime, 4), p. 11-34.

LEPLA, D., 2007 - Les Fossés Royaux (xiI ${ }^{\mathrm{e}}$ siècle) dans le département de l'Orne : la défense d'une frontière au sud du duché de Normandie. Cahiers percherons, 172, p. 19-34.

LEPROVOST, T., 2006 - Dreknor, aux sources du passé viking. Patrimoine normand, 60, p. 6-13.

LEPROVOST, T., 2006 - Du nouveau au château de Caen, les armoiries du dauphin. Patrimoine normand, 60, p. 61-69.

GUEGAN, R., 2006 - Le silence archéologique [matériel viking]. Pays de Normandie, 54, p. 26-27.

LEVALET, D. et NICOLAS-MÉRY, D., 2006 - Observations archéologiques autour d'un chantier du Scriptorial. Revue de l'Auranchin et du Pays de Granville, 83 (fasc. 407), p. 133-183.

GUEGAN, R., 2006 - Nos ancêtres les Vikings. Pays de Normandie, 54, p. 22-25.

MANEUVRIER, C., DELACAMPAGNE, F., SAVARY, X. et ALDUC-LE-BAGOUSSE, A., 2008 - Évrecy : de l'église abbatiale à l'église paroissiale (VII ${ }^{\mathrm{e}}$-XIV ${ }^{\mathrm{e}}$ siècles). La paroisse en Normandie au Moyen Âge, La vie paroissiale, l'église et le cimetière, Histoire - art - archéologie (Actes du colloque de SaintLô, 2002). Saint-Lô : Société d'Archéologie et d'Histoire de la Manche (Etudes et Documents, 27), p. 355-383.

MARETTE, F., 2007 - Essai d'identification des pierres rondes de Saint-Pair. Revue de la Manche, 49 (fasc. 196), p. 3-21.

MATHIEU, J.-N., 2007 - Le manoir et les seigneurs de SaintVaast-en-Auge. Le Pays d'Auge, 57 (n' ${ }^{\circ}$ 1), p. 6-17.

MOULIN, M.-A., CHAVE, I., FAJAL, B. et FOUCHER, J.-P. (dir.), 2008 - Argentan et ses environs au Moyen Âge, approche archéologique et historique. Alençon, Conseil général de L’Orne, $287 \mathrm{p}$.

NICOLAS-MÉRY, D., 2007 - Mélanges : une maison romane sous la place d'Estouteville [Avranches]. Revue de l'Avranchin et du Pays de Granville, 84 (fasc. 411), p. 171-181. 
NISSEN-JAUBERT, A., 2007 - L'église priorale de SaintSymphorien de Domfront. In, DELRIEU, F. et DESLOGES, J. (dir.), avec la coll. De QUÉVILLON, S., ArchéOrne : 250 ans d'archéologie dans l'Orne (catalogue d'exposition). Cabourg, éditions Cahiers du temps, p. 122.

NISSEN-JAUBERT, A., 2007 - Le château de Domfront. In, DELRIEU, F. et DESLOGES, J. (dir.), avec la coll. de QUÉVILLON, S., ArchéOrne : 250 ans d'archéologie dans l'Orne (catalogue d'exposition). Cabourg, éditions Cahiers du temps, p. 132-133.

OEIL DE SALEYS, S., 2007 - Lestre (Manche) : chapelle SaintMichel. Chroniques des fouilles médiévales en France en 2006. Archéologie médiévale, 37, p. 249.

PARISSE, M., 2006 - De l'usage de la propagande au Moyen Âge : la tapisserie de Bayeux. L'Histoire, 315, p. 58-63.

PILET, C., 2007 - Saint-Vigor-le-Grand (Calvados) : Pouligny, Delle des Baubignons. Chroniques des fouilles médiévales en France en 2006. Archéologie médiévale, 37, p. 299-300.

POIRIER, A., 2007 - La nécropole mérovingienne de Colombiers. In, DELRIEU, F. et DESLOGES, J. (dir.), avec la coll. de QUÉVILLON, S., ArchéOrne: 250 ans d'archéologie dans l'Orne (catalogue d'exposition). Cabourg, éditions Cahiers du temps, p. 123.

RIQUE, P., 2006 - Château de Falaise : pendant les travaux, le massacre continue. Patrimoine normand, 57, p. 24-25.

SEHIER, E., 2006 - Caractéristiques de l'activité textile au sein des habitats ruraux des $\mathrm{V}^{\mathrm{e}}-\mathrm{x}^{\mathrm{e}}$ siècles en Normandie. Bulletin de liaison de l'Association française d'Archéologie mérovingienne, 30 (XXVII $^{\mathrm{e}}$ journées internationales d'Archéologie mérovingienne, Caen 2006), p. 107-110.

TOURNIER, F., 2007 - Carentan (Manche) : place du Grand Valnoble. Chroniques des fouilles médiévales en France en 2006. Archéologie médiévale, 37, p. 254.

GUEGAN, R., 2006 - Tapisserie de Bayeux. Pays de Normandie, 54, p. 28-29.

\section{7. ÉPOQUES MODERNE ET CONTEMPORAINE}

BERNOUIS, P., DUFOURNIER, D. et LECHERBONNIER, Y., 2006 - Céramique architecturale en Basse-Normandie. La production de briques et de tuiles ( $\mathrm{XIX}^{\mathrm{e}}-\mathrm{XX}^{\mathrm{e}}$ siècles). Cabourg, Les Cahiers du Temps, $144 \mathrm{p}$.

BUFFETAUT, Y., 2007 - Circuit du fer dans l'Orne. Itinéraires de Normandie, 8, p. 78-83.
DELRIEU, F., 2006 - Cheffreville-Tonnencourt (Calvados). Extension du cimetière communal. Chronique des fouilles médiévales en France en 2005. Archéologie médiévale, 36, p. 252.

FAISANT, E., 2007 - Balleroy. Nouveaux documents sur la construction du château (1631-1637). Bulletin monumental, 165 (n' 4), p. 377-378.

GUICHARD, M., 2006 - L'exploitation des carrières de l'Orne de 1870 à 1939. Annales de Normandie, 56 e année, 4, p. 503520.

MANNEVILLE, P., 2007 - Le cimetière privé protestant de La Motte, à Athis (Orne) : actes du 165e congrès de l'Association normande pour les progrès de l'agriculture, de l'industrie, des sciences et des arts, Condé-sur-Noireau, 2007. Annuaire des cinq départements de la Normandie, p. 104-106.

MOUCHEL-VALLON, P., 2007 - Pots à beurre, ciminel et surets de Montroch : le développement d'un hameau de défricheurs et de potiers (Néhou, $\mathrm{XVI}^{\mathrm{e}}$-XvII ${ }^{\mathrm{e}}$ siècles). Revue de la Manche, 50 (fasc. 198), p. 23-39.

PATTE, E., 2007 - L'architecture en bauge dans les marais du Cotentin et du Bessin à l'époque moderne. In, PATTE, E. et STREIFF, F., L'architecture en bauge en Europe : actes du colloque d'Isigny-sur-Mer, 2006. Les Veys, Parc naturel régional des Marais du Cotentin et du Bessin, p. 133-149.

SAVARY, X., 2007 - La construction en terre crue dans le Calvados : de la prospection à la perspective de recherche. In, PATTE, E. et STREIFF, F., L'architecture en bauge en Europe : actes du colloque d'Isigny-sur-Mer, 2006. Les Veys, Parc naturel régional des Marais du Cotentin et du Bessin, p. 195-209.

TOURNIER, F., 2007 - La Glacerie (Manche) : rue de la Motterie. Chroniques des fouilles médiévales en France en 2006. Archéologie médiévale, 37, p. 323.

VILGRAIN-BAZIN, G., 2006 - Les moulins dans la Hague : inventaire. In, MARCIGNY, C. (dir.), Archéologie, Histoire et Anthropologie de la Presquî̀le de la Hague (Manche) : analyse sur la longue durée d'un espace naturel et social cohérent. (Deuxième année de recherche 2006, rapport de PCR). Beaumont-Hague, Le Tourp, p. 51-55.

WATTS, G., 2007 - Cherbourg (Manche) : CSS Alabama. Chroniques des fouilles médiévales en France en 2006. Archéologie médiévale, 37, p. 319. 
